\section{Sacerdotes, apropiación del discurso médico y experiencia mística en la Francia del siglo XIX}

\author{
Priests, the appropriation \\ of medical discourse and \\ mystical experience in \\ nineteenth-century France
}

\author{
Andrea Graus ${ }^{i}$ \\ Investigadora Marie Curie, Centre Alexandre Koyré/ \\ Centre National de la Recherche Scientifique. \\ París - Francia \\ orcid.org/0000-0002-9513-0048 \\ andrea.graus@cnrs.fr
}

Recebido em 24 fev. 2019.

Aprovado em 25 jul. 2019.
GRAUS, Andrea. Sacerdotes, apropiación del discurso médico y experiencia mística en la Francia del siglo XIX. História, Ciências, Saúde - Manguinhos, Rio de Janeiro, v.28, n.2, abr.-jun. 2021, p.455472.

\section{Resumen}

El artículo explora la apropiación de la terminología psiquiátrica por parte de teólogos y párrocos franceses, en el contexto de la patologización de la religión del siglo XIX. Esta apropiación le sirvió al clero para demarcar la experiencia mística "auténtica" de la simulada o "desviada". En primer lugar, analizamos manuales médico-teológicos pensados para crear una oposición entre la histeria y la santidad, útil desde el punto de vista eclesiástico. En segundo lugar, presentamos los informes de tres párrocos sobre presuntas místicas y estigmatizadas. Concluimos que la apropiación de la retórica médica por parte del clero podía servir para definir los límites de la experiencia religiosa aprobada por la Iglesia católica.

Palabras clave: misticismo; psiquiatría; histeria; ciencia y religión; Iglesia católica.

Abstract

This article explores the appropriation of psychiatric terminology by French theologians and priests, within the context of the pathologizations of religion in the nineteenth century. This appropriation allowed the clergy to differentiate "authentic" mystical experience from feigned or "deviant" ones. Firstly, it analyzes medical and theological manuals that sought to create an opposition between hysteria and saintliness, which was useful from the ecclesiastical point of view. Secondly, it presents the reports of three priests on supposed female mystics with stigmata. It concludes that the appropriation of medical rhetoric by the clergy could be used to define the limits of religious experience approved by the Catholic church.

Keywords: mysticism; psychiatry; hysteria; science and religion; Catholic church. 
$\mathrm{D}$ entro del contexto de medicalización de la religión que impregnó el siglo diecinueve encontramos confluencias entre la psiquiatría y la desviación religiosa entendida por teólogos y párrocos franceses. Nuestro objetivo es mostrar cómo el clero utilizó el discurso médico para crear fronteras epistemológicas entre experiencias místicas "auténticas" o "aprobadas" por la Iglesia católica, y experiencias "desviadas" o "desaprobadas". Según veremos, varios teólogos escribieron ensayos para ayudar al clero a diferenciar entre el éxtasis de las histéricas y el de los santos. A su vez, los párrocos se apropiaron de la terminología psiquiátrica de la época para presentar el comportamiento de supuestas místicas como una forma de desviación religiosa ante la autoridad diocesana.

El uso de las estrategias retóricas para crear fronteras epistemológicas se ha estudiado dentro del llamado boundary-work, representado por el sociólogo Thomas Gieryn. Inicialmente, Gieryn (1983) lo usó para analizar el problema de la demarcación científica. En su primer trabajo sobre boundary-work mostró que lo que se entiende por ciencia depende de intereses profesionales e ideológicos. Según argumentó, con frecuencia la demarcación científica es ambigua y depende de estrategias retóricas pensadas para presentar la ciencia como neutra, objetiva o racional. A pesar de que el bounday-work se ha asociado, especialmente, al examen de la demarcación entre ciencia y pseudociencia (Graus, 2015), desde un punto de vista socioconstructivista puede asociarse a otros casos para observar cómo las estrategias retóricas permiten delimitar dominios de conocimiento. Gieryn (1999, p.44), por ejemplo, también se ha interesado por la demarcación entre ciencia y religión en la Inglaterra victoriana, proceso que define como "una batalla por la autoridad cultural y epistémica". Un libro reciente, editado por Annette Mülberger (2016), ha analizado la cuestión de las fronteras científicas dentro del auge del espiritismo y la investigación con médiums durante la modernidad.

Al analizar la apropiación del discurso médico por parte del clero esperamos mostrar que, dentro de la Iglesia católica, la psiquiatría de la época no tenía por qué ser una amenaza para la experiencia religiosa, sino que podía servir para definirla y denunciar presuntos fraudes. Así pues, nuestro interés no radica, al menos no en exclusiva, en examinar la colaboración entre la Iglesia y los médicos para explicar supuestos milagros, o en la llamada patologización de la religión por parte de la psiquiatría de la época. Esta cuestión ha sido estudiada por historiadores que han examinado la redefinición de la experiencia mística y la posesión dentro de la medicina. Nicole Edelman (2003, p.208), por ejemplo, ha analizado la "patologización de la posesión, el éxtasis y las visiones" en la Francia anticlerical y librepensadora de la segunda mitad del diecinueve. Dicha patologización se realizó, principalmente, mediante el diagnóstico de la histeria y siguiendo, ante todo, la concepción de la Escuela de la Salpêtrière (Carroy, 1981). Partiendo del mismo contexto histórico que Edelman, Jacques Maître (1999, p.772) ha puesto de manifiesto el legado de la "explicación de la mística a través de la patología" en casos contemporáneos, como los de la estigmatizada Marthe Robin (1902-1981). Esta clase de historiografía ha sido influenciada por autores como Michel de Certeau, quien también se preocupó por las formas contemporáneas de apropiación médica y psicológica del místico, entendido como un "objeto de conocimiento" de estas áreas (Certeau, 2015, p.14; Marques, 2010).

Otra clase de historiografía se ha interesado por ofrecer una visión más matizada de la interacción entre la medicina y la religión, más allá de la patologización por parte de 
médicos y psiquiatras. Hervé Guillemain (2006) ha mostrado la importancia de los médicos para la Iglesia a partir de 1860 en Francia, donde, entre otras cuestiones, emprendieron roles de directores de conciencia mediante la terapia psiquiátrica. En el contexto inglés, Roy Porter (2003) ha observado que los charlatanes promocionaron sus remedios como curas milagrosas y sus habilidades como dones divinos para dar legitimidad a sus prácticas médicas. Centrándose en la Alemania del romanticismo, Luis Montiel (2006) se ha ocupado de la interacción entre la medicina, el mesmerismo y lo sobrenatural. Mediante casos como el del doctor Justinus Kerner y sus pacientes videntes y posesas, ha mostrado que lo racional y lo místico no siempre se oponían.

Un libro reciente, editado por Tine Van Osselaer, Henk De Smaele y Kaat Wils (2017), también apuesta por ofrecer una visión más productiva de la interacción entre medicina y religión. Como remarca Van Osselaer (p.12-13) en la introducción, a pesar de que las historiografías sobre la patologización religiosa se han centrado en contextos "prototípicos" como la Tercera República Francesa (1870-1940), las categorías y discursos asociados a este contexto, como el anticlericalismo y la histeria, funcionaban de manera distinta o con anterioridad en otros periodos y países. A este respecto debemos mencionar el trabajo de Sabine Arnaud (2015) sobre la construcción médica de la histeria mediante estrategias discursivas entre 1670 y 1820, así como el análisis de rebelión femenina que Jan Goldstein (2011) hizo del caso de la extática e "histérica" Nanette Leroux en los años 1820.

En relación con los intercambios epistemológicos entre ciencia y religión, cabe destacar los trabajos del historiador Tiago Pires Marques. Centrándose en casos de visionarias y estigmatizadas portuguesas de principios del siglo XX, Marques ha mostrado cómo la psiquiatría, y en particular categorías como la histeria, también penetraron el contexto religioso de la mano de sacerdotes y médicos católicos. Estos llevaron a cabo una apropiación del conocimiento psiquiátrico para construir una "ciencia mística", en términos de Certeau (2015, p.3), capaz de acomodar la experiencia religiosa y la medicina (Marques, 2017, 2016). En algunos de los ejemplos de visionarias y estigmatizadas analizados por Marques (2017, p.151), "la 'mujer histérica' se convirtió en el contraejemplo típico de la auténtica experiencia religiosa". Otros trabajos centrados en las ayunadoras (inedia) portuguesas y gallegas han mostrado que estos casos representan una frontera híbrida entre la historia de la religión, la cultura popular y la psiquiatría (Bustos-Cardona et al., 2015). El presente artículo parte de problemáticas similares a las de Marques en la medida en que la apropiación del discurso psiquiátrico, incluyendo nociones de histeria, sirvió a teólogos y párrocos para definir los límites epistemológicos de la experiencia mística "verdadera" y simulada en la Francia del diecinueve.

Historiadores como Thomas Kselman (1983) han mostrado que este periodo, a pesar del anticlericalismo y la ofensiva positivista, fue un momento de renacimiento católico, especialmente con respecto a la religión popular. Dentro de la comunidad católica, los acontecimientos "traumáticos" asociados a la época, como la derrota de Francia en la guerra franco-prusiana y la Comuna de París, generaron la idea de que la nación estaba siendo castigada por sus "pecados" contra la religión. La necesidad de los católicos por expiar dichos pecados se ha relacionado con el auge de las peregrinaciones, las apariciones marianas o el renacimiento de cultos redentores como la devoción del Sagrado Corazón 
(Burton, 2005). Vale la pena recordar que el proyecto de la basílica del Sacré-Coeur en París se empezó a gestar a principios de los años 1870, alimentado por el espíritu de redención tras la derrota franco-prusiana.

La historiografía ha destacado que, a diferencia de lo ocurrido en otras épocas, el misticismo católico del siglo XIX se ha hecho conocido por su carácter popular, generalmente encarnado por campesinas jóvenes, así como por el énfasis en los aspectos corporales de la experiencia religiosa, como el éxtasis (Blackbourn, 1993; Maître, 1997). Si pensamos en las místicas francesas más recordadas de la época, como Bernadette Soubirous, la visionaria de Lourdes (1858), vemos que encajan dentro de este perfil (Harris, 2008). Otro fenómeno corporal en boga durante la época fueron los estigmas, donde las llagas aparecían en el cuerpo de los místicos estigmatizados, en su mayoría mujeres, quienes decían revivir la Pasión los viernes (Bouflet, 1996; Van Osselaer et al., 2020). Al mismo tiempo, dentro del misticismo católico, especialmente en Francia, se desarrolló una tradición profética de trasfondo apocalíptico y milenarista, la cual hablaba del regreso de un "gran rey" que salvaría Francia y la Iglesia (Curicque, 1872). Dichas profecías alimentaron las esperanzas de los legitimistas, aristócratas y ultramontanos, quienes ansiaban la restauración monárquica, encarnada inicialmente en la figura del conde de Chambord (Henri V), pretendiente borbónico al trono (Multon, 2003).

Todos estos fenómenos, desde éxtasis, apariciones y estigmas, fueron supuestamente experimentados por las místicas que mencionamos en este artículo. Asimismo, sus casos fueron refutados mediante la apropiación del discurso médico en los informes de los párrocos. Dichos informes provienen de archivos diocesanos franceses en Burdeos, Rouen y Nantes. En general, formaban parte de la correspondencia mantenida entre los párrocos y los vicarios o los obispos para mantenerse informados de supuestas "santas vivientes" en sus diócesis. Antes de centrarnos en esta cuestión, analizaremos algunos ensayos de teólogos franceses que también se apropiaron de categorías psiquiátricas para distinguir el auténtico misticismo y la santidad de la histeria u otras neurosis. Sus obras aparecieron en el contexto de laicización y anticlericalismo que alimentó los discursos médicos sobre la histeria, los cuales permitieron atacar la religión desde la psiquiatría positivista en Francia.

\section{La patologización de la experiencia religiosa}

En Francia, el auge del misticismo y la religión popular tuvo lugar en un momento de cuestionamiento de los milagros y otros fenómenos sobrenaturales. Dentro del ámbito teológico y de la historia, los debates sobre la Biblia pusieron en duda los milagros evangélicos. Este proceso se dio en las biografías históricas de Jesús, desde la erudita de David Strauss (1856) publicada en 1835, en alemán, hasta la más popular de Ernest Renan (1863) en francés, las cuales crearon un gran revuelo en Europa (Craig, 1986; Simon-Nahum, 2007). Con respecto a la medicina y psiquiatría, las nuevas formas de entender lo normal y lo patológico contribuyeron a atacar la religión.

Según Georges Canguilhem (2003) e Ian Hacking (1990), quien se inspiró en el primero, la idea del "estado normal", entendido como el promedio, data del siglo XIX. Hasta entonces el estado normal se consideraba un estado completamente distinto del patológico. 
Mediante científicos y pensadores como François Broussais y Auguste Comte, fundador del positivismo, lo patológico o "anormal" pasó a definirse como una "desviación" de lo normal. Los fenómenos de la enfermedad y de la salud serían los mismos, pero diferirían en intensidad. Para Canguilhem (2003, p.180), lo normal no es un promedio estadístico, sino que forma parte un proyecto normativo dentro de un sistema social. La cuestión de lo normal entendido como norma o valor también ha sido desarrollada por Michel Foucault en su análisis de los dispositivos de normalización, entre ellos el científico (Bacarlett Pérez, Lechuga de la Cruz, 2009). Según Hacking (1990, p.168), en la Francia del diecinueve, el estado normal estuvo intrínsecamente asociado a una idea del progreso basada en el positivismo, el cual a su vez influyó las políticas republicanas de laicización (Eros, 1955). En este contexto, la experiencia religiosa, en especial el misticismo y la posesión, empezaron a entenderse como una desviación patológica o una anormalidad propia de la superstición y alejada del positivismo y el progreso científico que ejercían de norma.

La patologización de la experiencia religiosa empezó dentro del alienismo. En 1790, Philippe Pinel denunció el carácter patológico de la vida religiosa, mientras que la escuela de Esquirol instaló la oposición entre ciencia y religión a partir de 1830. Para alienistas como Esquirol y, posteriormente, Louis-Francisque Lélut y Louis-Florentin Calmeil, fenómenos místicos como el éxtasis o las visiones no eran más que alucinaciones de carácter patológico. Mediante sus discursos, crearon una simetría entre la "locura religiosa" del pasado y los casos clínicos observados en los asilos (Guillemain, 2006; Marques, 2010). Sus argumentos se propagaron gracias a escritos como los del médico Alfred Maury en la revista Annales Médico-psychologiques. La primera publicación de Maury en esta revista fue una reseña de un polémico libro sobre las alucinaciones, del alienista católico Alexandre Brierre de Boismont (1845). En ese texto, Brierre de Boismont defendió que el éxtasis o las comunicaciones divinas, a pesar de ser alucinatorias, eran compatibles con la razón en los casos de célebres santos y visionarios católicos. En su reseña, Maury (1845) acusó Brierre de Boismont de defender la doctrina católica al negar la locura y las alucinaciones patológicas de personajes como Juana de Arco, supuestamente probadas por el alienismo.

Como afirma Jean-Christophe Coffin (2007, p.91), Maury mostraba "una cierta propensión a declarar patológico aquello que es considerado por otros como signos de fervor religioso". Esta actitud se constata en otro artículo de 1855, donde refutó experiencias religiosas como el éxtasis y la estigmatización mediante la tesis racionalista de la imaginación. Según Maury, los místicos estigmatizados vivían envueltos por imágenes de la crucifixión y tenían largas meditaciones sobre la Pasión. Fijar la imaginación en dichas imágenes podía provocar el sangrado de los supuestos estigmas, especialmente en mujeres, quienes, dada la menstruación, estaban naturalmente predispuestas para producir esta clase de fenómenos (Maury, 1855). Maury (1860) continuó la elaboración de sus enfoques racionalistas sobre la experiencia mística en un ensayo posterior titulado La magia y la astrología (La magie et l'astrologie) (Richard, 2007).

Entre aquellos que atacaron a Maury hallamos médicos católicos como Antoine ImbertGourbeyre. De carácter conservador y legitimista, Imbert-Gourbeyre se convirtió en un acólito de los místicos extáticos y estigmatizados y fue autor de varias obras sobre el tema. En ellas se enfrentó a las tesis racionalistas para defender la posibilidad del origen divino 
de los fenómenos (Imbert-Gourbeyre, 1873, 1894, 1899). Sus intenciones, sin embargo, también tenían un trasfondo político. En efecto, el devoto médico formaba parte del gran número de aristócratas y miembros de la alta burguesía francesa que volcaron sus esperanzas legitimistas en las místicas o "santas vivientes" de la época. Como ha mostrado Jacques Maître (1999), la "cultura católica del milagro" fue la estrategia usada en estos casos para promover el ultramontanismo y la reconquista católica de la Francia anticlerical y republicana. El entusiasmo de Imbert-Gourbeyre por algunas estigmatizadas fue sancionado por el Vaticano, quien impidió la reimpresión de uno de sus libros (Klaniczay, 2020; Sandoni, 2015). A pesar de ello, Imbert-Gourbeyre (1894) obtuvo permisión eclesiástica para una obra posterior sobre el fenómeno de la estigmatización, donde atacó los "librepensadores" de la Salpêtrière.

Los empeños de Imbert-Gourbeyre respondieron pues al embate anticlerical contra la religión, el cual tuvo lugar, especialmente, desde la Tercera República Francesa (1870-1940). Como es bien sabido, el contexto francés del fin-de-siècle estuvo fuertemente influenciado por las políticas de laicización, las cuales culminaron con la ley de 1905 para la separación de la Iglesia y el Estado. A su vez, estas políticas alimentaron el discurso médico de la grande hystérie en la Salpêtrière de París, quien se unió a las campañas republicanas y abanderó la patologización de la experiencia religiosa mediante la tan discutida categoría de la histeria. Para Charcot y sus colaboradores, casos famosos de supuestas posesiones, misticismo y curas milagrosas, tanto pasados como contemporáneos, formaban parte del discurso médico de la histeria (Carroy, 1981; Mazzoni, 1996). Mediante la aserción de que la histeria era una enfermedad universal, la Salpêtrière acusó la Iglesia católica de haber quemado y torturado mujeres inocentes a lo largo de la historia mediante acusaciones de brujería y posesión diabólica (Charcot, Richer, 1887). Este proceso de patologización de la experiencia religiosa contribuyó al proyecto de laicización de la Tercera República. En palabras de Jan Goldstein (1982, p.236; énfasis adicional), "la redefinición de lo sobrenatural como natural-'patológico' fue más allá y tuvo el efecto de desacreditar la religión; estaba en consonancia con la frenética cruzada por la laicización que marcó la política republicana de esta época".

Otros casos fuera de la religión oficial, como por ejemplo los médiums espiritistas, en auge en la misma época, corrieron la misma suerte que los místicos y santos y fueron encasillados dentro de los diagnósticos de las alucinaciones y el desdoblamiento de la personalidad (Graus, 2019; Le Maléfan, Evrard, Alvarado, 2013). Las teorías sobre el desdoblamiento, en las que los espíritus eran considerados personalidades subconscientes del médium, fueron formuladas por médicos como Pierre Janet, también en el caso del misticismo. Según Janet (1898), los fenómenos donde intervenían supuestas apariciones y espíritus eran análogos a los del sonambulismo, de modo que podían explicarse mediante mecanismos como la autosugestión. No por casualidad, las dos pacientes más famosas de Janet fueron la sonámbula Léonie Le Boulanger en El Havre, y la mística Madeleine Lebouc en la Salpêtrière (Janet, 1975; Maître, 1993a). Como Nicole Edelman (2006) ha mostrado, los espiritistas franceses se opusieron a las teorías del sonambulismo y el desdoblamiento de la personalidad, e incluso desarrollaron terapias espíritas para curar presuntas histéricas. 
A pesar de los embates positivistas, la Iglesia católica no negó la existencia de la histeria y otras patologías atribuidas a supuestos místicos. Sin reconocer completamente los argumentos de la Salpêtrière, admitió que en la histeria se podían simular estados de frenesí religioso y otros fenómenos. La relación entre medicina y religión no era una novedad ya que, desde al menos el siglo XIII, los médicos habían participado en las causas de canonización para evaluar milagros como las curas milagrosas. Su implicación aumentó desde el siglo XVII, momento en que se adoptó una actitud más escéptica y se empezó a dar más importancia a las explicaciones naturales de los milagros (Duffin, 2009; Vidal, 2007). Casos más contemporáneos, como las curas milagrosas de Lourdes, han servido a los historiadores para analizar el papel de los médicos católicos en la modernidad. Entre otras cuestiones, se ha examinado la construcción de la credibilidad científica en sus análisis (Szabo, 2002), así como la evolución de las evaluaciones médicas de los milagros con respecto al discurso científico dominante y la Iglesia católica (Ogorzelec, avril-juin 2014). En este sentido, desde el inicio de la colaboración entre la medicina y la religión hubo apropiaciones epistemológicas, las cuales la Iglesia católica utilizó para demarcar los límites de lo sobrenatural.

\section{Teólogos franceses y apropiación del discurso médico}

En el siglo XIX en particular, la desviación patológica o la anormalidad atribuida a la experiencia religiosa, tal y como la definía la psiquiatría de la época, convino a la Iglesia a la hora de diferenciar entre experiencias místicas verdaderas y falsas. Como la historiadora Nicole Edelman (2003, p.211) ha mencionado, durante la Tercera República Francesa los sacerdotes acudían con más frecuencia a los médicos, en lugar de a los exorcistas, para examinar supuestos casos de misticismo y posesión en su diócesis. Jacques Maître (1999, p.772) también ha constatado que, dentro del mundo eclesiástico, "a medida que la demonología declinaba, el falso misticismo fue cada vez más atribuido a trastornos neuropsíquicos". Así, en el vocabulario de los clérigos franceses, términos como histeria comenzaron a sustituir los conceptos tradicionales utilizados en oposición a la santidad y al misticismo, principalmente: la posesión diabólica.

Entre los teólogos franceses que utilizaron los discursos médicos en boga destacan el jesuita Joseph de Bonniot (1831-1889) y el trapense Jean Corneille Debreyne (1786-1867). Ambos escribieron ensayos los cuales, a modo de manual, debían ayudar al clero a distinguir la santidad y el misticismo de las neurosis y otros estados alterados de conciencia. El historiador Mark Micale (1995) ha interpretado la posición de Bonniot en términos de oposición entre religión y ciencia. A nuestro entender, más que un mero ataque de la psiquiatría positivista, tanto Bonniot como Debreyne llevaron a cabo una apropiación del discurso psiquiátrico para presentar los casos de "falso" misticismo como una desviación patológica la cual no anulaba la posibilidad de la experiencia mística auténtica. Para ello, no bastaba con refutar el discurso médico, sino que había que amoldarlo para que favoreciese los intereses eclesiásticos. Como veremos seguidamente, si bien los teólogos definieron el "verdadero" misticismo en contraposición, principalmente, a la histeria, dicha oposición contribuyó a definir los límites de la santidad y la experiencia religiosa aprobada por la Iglesia católica. 
Debreyne, quien además era doctor en medicina, llevo a cabo esta particular apropiación del discurso médico en su Essai sur la théologie morale considérée dans ses rapports avec la physiologie et la médecine (Ensayo sobre la teología moral considerada en su relación con la fisiología y la medicina), de 1842, cuya primera edición fue reeditada y expandida en múltiples ocasiones. Los textos más representativos de Bonniot en este aspecto son Le miracle et les sciences médicales (El milagro y las ciencias médicas), de 1879, y Opposition entre l'hystérie et la sainteté (Oposición entre la histeria y la santidad), de 1886. En sus obras, ambos teólogos compararon los síntomas de la histeria, las alucinaciones o la anorexia, identificados en la literatura médica, con el comportamiento y los fenómenos místicos experimentados por los santos contemporáneos y pasados. Por ejemplo, confrontaron la tendencia a la simulación, la desobediencia y la vanidad atribuida a las histéricas, con las virtudes heroicas y la obediencia eclesiástica de místicos y santos como Catalina de Siena (Bonniot, 1886; Debreyne, 1884).

Con respecto a fenómenos corporales típicamente asociados a la experiencia mística, como el éxtasis, los argumentos de Bonniot se construyeron explícitamente en contra de la teoría detrás de la grande hystérie de la Salpêtrière, donde el fenómeno del éxtasis formaba parte de la tercera fase del ataque histérico. Esta fase, llamada "actitudes pasionales", incluía síntomas como estados emocionales alterados y la suspensión de la inteligencia (Lakhdari, 2007). En un artículo dedicado a la histeria y el sonambulismo, el fisiólogo Charles Richet (1880, p.358) explicó que la tercera fase del ataque histérico era "el momento donde se dan alucinaciones de todo tipo, tanto felices, como tristes, amorosas, religiosas o extáticas.... [La histérica] cruza los brazos y eleva los ojos al cielo en una actitud de admiración religiosa, como si viera las nubes entreabrirse para mostrarle santos o dioses". Richet tituló el artículo "Las demoniacas de hoy", en referencia a que las antiguas posesas eran las actuales histéricas.

Según Bonniot (1886, p.35), el éxtasis de los santos no era un "ataque" como el de los histéricos, descrito por Richet y tantos otros, que paraliza el cuerpo, los sentidos y sustrae la voluntad: "el extático [santo] no está paralizado, solo está distraído; sus órganos se hallan en la inmovilidad del reposo, y no en la inmovilidad de la impotencia; sus funciones exteriores, para reprender su tarea, solo necesitan del retorno de la atención". En este sentido, la condición humana no se hallaba perturbada durante una auténtica experiencia religiosa, dentro de la cual el místico preservaba, o incluso sublimaba, su moral y sus funciones intelectuales.

Debreyne (1884) fue de la misma opinión. En sus palabras, durante la "verdadera" experiencia mística, "la inteligencia toma un poderoso auge, donde la conciencia no sufre para nada, al contrario; y la fuerza moral que resulta de ella aumenta, al mismo tiempo que se confirma el buen equilibrio de las fuerzas físicas" (p.272-273). El éxtasis era pues, al contrario de las "actitudes pasionales" de la grande hystérie, un momento de serenidad, equilibrio y apogeo que no afectaba negativamente al libre albedrío. De este modo, estos teólogos argumentaron que la histeria $u$ otras neurosis eran incompatibles con la experiencia religiosa auténtica. Por lo tanto, según los teólogos mencionados, no podían existir santos o místicos histéricos, tal y como se afirmaba en la psiquiatría de la época, sino solo histéricos que fingían ser santos o místicos.

Además de clarificar varios conceptos psiquiátricos desde el punto de vista teológico, los ensayos de Bonniot y Debreyne se pensaron como manuales para los sacerdotes, los 
cuales les tenían que ayudar a distinguir entre la neurosis y la verdadera experiencia mística en su parroquia. Para ello, usaron ejemplos reales de curas que se enfrentaban a casos de presunto misticismo, y los compararon con casos clínicos y con los santos. Debreyne, por ejemplo, transcribió la correspondencia mantenida en 1840 con un sacerdote con respecto a una joven, internada en un hospicio religioso en el norte de Francia, que decía haber experimentado fenómenos místicos como el éxtasis y los estigmas durante los dos últimos años. Según el sacerdote, la mujer no era una santa, como ella misma se pretendía, sino una "débil mental". Debreyne le dio la razón. Aportó razones fisiológicas para explicar fenómenos místicos como los estigmas y atribuyó su aparición al deseo de la mujer de ser admirada (Debreyne, 1868, p.353-362). Sus explicaciones podrían haber emanado de cualquier médico escéptico; sin embargo, en su caso no anulaban la posibilidad de la experiencia mística auténtica. Mediante este y otros ejemplos, Bonniot y Debreyne mostraron al clero cómo diferenciar fenómenos místicos como el éxtasis, la inedia y las visiones, de la catalepsia, anorexia o alucinaciones. Todo ello se realizó mediante estrategias retóricas de demarcación, sin negar la posibilidad de la simulación y apropiándose de la patologización de la experiencia religiosa.

Queda claro que, desde el punto de vista eclesiástico, los teólogos franceses hicieron uso de los enfoques psiquiátricos de la anormalidad o la desviación patológica atribuida al misticismo para definir formas "verdaderas", o más bien "aprobadas", de la experiencia mística. ¿Tuvo este discurso una traducción práctica? Más allá de los ejemplos aportados por los teólogos, ¿utilizaron los sacerdotes la apropiación del discurso médico al verse confrontados ante posibles casos de misticismo? A continuación examinamos los informes de tres párrocos sobre presuntas místicas francesas a finales del siglo XIX. Según argumentaremos, la apropiación de términos presentes en la psiquiatría y medicina permitió definir los límites de la experiencia religiosa en el día a día.

\section{Párrocos, terminología psiquiátrica y presuntas místicas}

En Francia, como en otros países, los obispos buscaban mantenerse informados sobre casos de misticismo, curas milagrosas, apariciones y fenómenos similares mediante los párrocos. Ellos eran los encargados de redactar informes o mantener un diario sobre los hechos. Especial preocupación generaban los casos de pretendido misticismo donde la persona (generalmente una mujer) adquiría la fama de "santa viviente". Por un lado, la admiración de una persona viva está altamente desaconsejada por la Iglesia católica. Por otro lado, la devoción popular por dichas "santas" podía poner en entredicho la autoridad eclesiástica, quien en muchas ocasiones se posicionó en su contra. Desde el punto de vista eclesiástico, existió un interés por presentar las experiencias de supuestas místicas como desviaciones religiosas de carácter patológico. De este modo, se evitaba que los cultos no oficiales prosperaran.

Varios historiadores y antropólogos de la religión se han ocupado de las sectas y los cultos no oficiales durante la modernidad y la época contemporánea. En su análisis de los movimientos marianos, Peter Jan Margry (2004) ha definido esta clase de cultos como "devociones desviadas". Según Margry, las devociones desviadas se propagan desde abajo, 
desde los creyentes, y no están reconocidas por la Iglesia. A pesar de que Margry relaciona su ascenso con la segunda mitad del siglo XX, existen muchos ejemplos en épocas anteriores. En el contexto francés, el jansenismo, movimiento religioso herético originario del siglo XVII, es uno de los casos más conocidos. En particular, Serge Maury (2019) se ha ocupado de una secta convulsionaria jansenista de finales del dieciocho y de su carismática profeta, soeur Élisée. En relación con la Francia contemporánea, cabe destacar los trabajos de JeanPierre Chantin (2004) sobre las "sectas" o las disidencias religiosas y sus líderes, desde milenaristas y ocultistas a místicas seglares como las que presentamos seguidamente.

Los casos de Laurentine Billoquet, Marie-Julie Jahenny y Berguille Bergadieu, tres místicas estigmatizadas, visionarias y profetisas, generaron un gran revuelo en las diócesis de Rouen, Nantes y Burdeos, respectivamente. Como ha mostrado Jacques Maître (1997), esta clase de místicas alimentaron "devociones desviadas", por ponerlo en términos de Margry (2004), que combatían el laicismo de la Tercera República mediante la exaltación del milagro. A su vez, la devoción por estas "santas vivientes" representaba una amenaza para la autoridad diocesana, que se manifestó en contra de los dones carismáticos de dichas mujeres. Según mostraremos a continuación, los informes de los párrocos sobre las místicas utilizaron la terminología médica de la época para deslegitimar sus casos. A pesar de que la mayoría de los sacerdotes no tenían un conocimiento experto de términos como histeria, hipnosis o neurastenia, su uso les permitió señalar aquello que percibían como un comportamiento desviado o patológico desde el punto de vista médico y religioso, el cual podía ser objeto de sanciones.

\section{Laurentine Billoquet (Rouen)}

Laurentine Billoquet (1862-1936) nació en un pueblo cercano a Rouen en 1862. A la edad de 12 años tuvo su primera visión de la Virgen. En uno de sus diálogos espirituales, la Virgen le comunicó que la cruz era el camino de la salvación. En junio de 1881, el día de la Ascensión, Billoquet sintió un profundo dolor en sus manos, costado y pies, y las llagas de la Pasión aparecieron en su piel (Maître, 1993b). El doctor de la familia examinó las heridas con un grupo de médicos de París, entre los cuales se hallaba el reconocido neurólogo del asilo de Sainte-Anne, Benjamin Ball, antiguo alumno de Charcot en la Salpêtrière. El comité concluyó que el fenómeno era un fraude y consideró que Billoquet era una histérica que se deleitaba con simular éxtasis y ser admirada. Un informe sobre el caso apareció en la revista médica L'Encéphale, cofundada por el propio Ball ese mismo año, sin citar el nombre de Billoquet (Ball, 1881); sin embargo, la noticia se difundió rápidamente y los peregrinos comenzaron a llegar al pueblo. Para evitar el entusiasmo religioso, el episcopado de Rouen publicó una declaración en La Semaine Religieuse advirtiendo a los fieles que visitar a Billoquet significaba "obedecer una curiosidad malsana que la religión desaprueba" (Diocèse de Rouen, 1881, p.1007).

Por entonces corrían rumores de que el párroco, el padre Gauger, habría ayudado a Billoquet a preparar un fraude para atraer fieles a su parroquia. Ante este hecho, el sacerdote fue sustituido por el padre Hermier, a quien se le encargó redactar un diario (1883-1886) sobre la evolución de la supuesta mística. Como sucesor de Gauger, el padre Hermier se 
mantuvo extremadamente vigilante con Billoquet. Siguió los consejos eclesiásticos y la trató como a una "persona ordinaria", sin tener en cuenta sus supuestas experiencias religiosas y negándole la comunión diaria (Hermier, 31 ago. 1886). El diario y los informes que el párroco envió al vicario general nos muestran cómo la apropiación del vocabulario médico de la época le sirvió para afrontar el caso. En sus informes se refirió a Billoquet con expresiones como "la hipnotizada" o "la neurótica" (véase, por ejemplo, Hermier, 22 dic. 1885, 31 ago. 1886). Asimismo, bromeó frecuentemente sobre los inconvenientes "de tener a mujeres histéricas como feligresas" (Hermier, 17 feb. 1886). Entre otros problemas, argumentó que la condición de Billoquet podía alterarse fácilmente si él, en tanto su confesor, no consentía a sus deseos. La representación que hizo de Billoquet se ajustaba pues a la idea prototípica de la histérica como a la mujer caprichosa, infantil y narcisista; idea que, según hemos visto, era ampliamente representada en los textos médico-teológicos de la época.

Existen varios ejemplos que nos muestran que el padre Hermier se mantuvo informado sobre los enfoques psiquiátricos de los milagros, el éxtasis y otros fenómenos místicos en la literatura médica. En uno de sus informes, el padre Hermier llegó a referirse a Billoquet como a "mi "épileptico-hystérico-anesthésique"” (Hermier, 22 dic. 1885; énfasis en el original). Para este apodo, se inspiró muy probablemente en la obra del neurólogo Paul Richer, colega de Charcot en la Salpêtrière, quien había publicado recientemente su famoso libro Études cliniques sur la grande hystérie ou hystéro-épilepsie (1881), reeditado en 1885 . Hermier incluso comunicó al vicario su propia hipótesis científica sobre las llagas de Billoquet. Para ello, se refirió a los experimentos en hipnotismo de los doctores Henri Bourru y Prosper Burot (1888), quienes habían provocado hemorragias en sus pacientes mediante la sugestión (Hermier, 22 dic. 1885). La explicación del padre Hermier se hallaba en plena concordancia con el contexto científico del momento. No en vano los años 1880 fueron la época dorada del hipnotismo, especialmente en Francia, y la mayoría de los médicos reconocían el poder de la sugestión para provocar hemorragias cutáneas (Guillemain, 2006). Incluso, en países de mayoría protestante, como Gran Bretaña, algunos sacerdotes se habían librado a la práctica del mesmerismo (Winter, 1998). Si bien la Iglesia católica se mostraba reticente a aceptar la hipnosis y su precedente, el magnetismo animal, considerándolos peligrosos para el libre albedrío o incluso diabólicos (Franco, 1888; Diéguez-Gómez, 2003), dichas explicaciones parecían tolerarse en casos de "desviaciones religiosas", como el misticismo de Billoquet.

\section{Marie-Julie Jahenny (Nantes)}

El padre Audrian, párroco de Blain, pintó un retrato similar de otra famosa mística estigmatizada de la época, contemporánea de Billoquet, llamada Marie-Julie Jahenny (18501941). Jahenny era una joven campesina de La Fraudais, una aldea cercana al pueblo de Blain y a la ciudad de Nantes, en la Bretaña. Del mismo perfil místico que Billoquet, desde marzo de 1873 empezó a tener visiones de la Virgen, a revivir el éxtasis de la Pasión los viernes y a profetizar sobre el retorno de la monarquía en Francia. Las llagas serían visibles casi hasta su muerte en 1941 y su fama se extendió más allá del país galo. Desde sus inicios, la mística atrajo centenares, incluso, en al menos una ocasión, miles de personas a la aldea, y despertó las sospechas de la diócesis de Nantes. El mismo mes de marzo de 1873 en que 
empezaron los fenómenos, el obispado abrió una investigación y encargó a dos médicos católicos liberales, Jouon y Vignaux, el examen de Jahenny. Los médicos concluyeron que los fenómenos de éxtasis y estigmatización eran provocados y que la mística sufría de "crisis nerviosas" (Jouon, Vignaux, 29 mar. 1873).

Como ha argumentado Hervé Guillemain (2006, p.143), a pesar de que Jouon y Vignaux no usaron el término histeria, la descripción estereotipada que hicieron de Jahenny coincidía con dicha imagen. Otro médico católico, el citado Antoine Imbert-Gourbeyre (1878-1892), de carácter legitimista y seguidor de esta clase de místicas, examinó a Jahenny el mismo año y abogó por el origen divino de los estigmas, en cuyo caso, dijo, la Iglesia tenía la última palabra. A pesar de que Imbert-Gourbeyre logró convencer al obispo de Nantes, Monseñor Fournier, este murió al cabo de poco y los obispos que le sucedieron, así como los párrocos, jamás sostuvieron a Jahenny (Roberdel, 1987).

Los informes del padre Audrian, el párroco encargado de supervisar Jahenny en esa época, se decantaron por apoyar el examen médico negativo que tuvo lugar durante la investigación diocesana. En 1877, preparó un dosier para el obispo con el fin de demostrar que el comportamiento de la supuesta mística, y por lo tanto su experiencia religiosa, eran incompatibles con la santidad. Entre otros rasgos de Jahenny destacó sus mentiras, su falta de modestia y su insubordinación a la autoridad eclesiástica. Argumentó que, contrariamente a san Francisco de Asís, que solo mostraba los estigmas con disgusto para obedecer a sus superiores, Jahenny estaba encantada con recibir visitas y mostrar las llagas durante el éxtasis de la Pasión (Audrian, 15 oct. 1877). Apuntó que los médicos Jouon y Vignaux (29 mar. 1873) habían llegado a conclusiones similares en su informe, donde argumentaron que la fértil imaginación de Jahenny, su débil religiosidad y su deseo de mostrar las llagas eran contrarios a lo que cabría esperar de un santo. Con la intención de retomar el vocabulario empleado por los médicos mencionados, el padre Audrian (15 oct. 1877) también describió el éxtasis de Jahenny como una "crisis nerviosa". Así, Audrian utilizó la comparación entre la histeria y la santidad, presente en los manuales médico-teológicos y en los informes médicos de la investigación diocesana, para refutar la experiencia mística de Jahenny y presentarla como un fraude ante el obispado.

\section{Berguille Bergadieu (Burdeos)}

El padre Miramont, párroco de Fontet y confesor de Marie Bergadieu (1829-1904), más conocida como Berguille, utilizó una estrategia similar para refutar a esta otra visionaria francesa, contemporánea de las anteriores, que utilizaremos como último ejemplo. Bergadieu era una campesina de Fontet, un pueblo cercano a Burdeos, y madre de tres hijos. Decía estar en contacto espiritual con Marie-Julie Jahenny y revivir el éxtasis de la Pasión al mismo tiempo que ella cada viernes. Como Jahenny, hizo múltiples profecías sobre la restauración monárquica en Francia, presenció varias apariciones de la Virgen y fue objeto de una cura milagrosa. A pesar de que nunca fue reconocida por la Iglesia, obtuvo el apoyo de algunos sacerdotes, como el padre Daurelle, cuyo libro sobre los acontecimientos de Fontet fue censurado por el Vaticano (Daurelle, 1878). Al igual que las otras místicas mencionadas, Bergadieu se convirtió en una celebridad religiosa durante su vida y centenares de personas 
visitaron su aldea para ser testigos de sus profecías y éxtasis (Lachapelle, 2017). Algunos médicos, en su mayoría de la región, examinaron el caso y publicaron sobre "la extática de Fontet" sin mencionar su nombre. En general, concluyeron que la mística sufría de alucinaciones e histeria, además de simular sus éxtasis (Desmaisons, 1876; Girard, 1876; Mauriac, Verdalle, 1875).

El padre Miramont se mantuvo alerta sobre las explicaciones psiquiátricas sobre el caso. En sus informes al vicario general de Burdeos denunció "el indecente modo en que cada viernes [Bergadieu] hace su famoso viacrucis". Al parecer, la estigmatizada encarnaba a Cristo "vestida con un simple camisón y una enagua muy corta", acostada en la cama con las piernas desnudas y de una manera tan sugestiva que obligaba, según Miramont, "a mirar hacia otro lado". Todo ello sucedía en medio de una "excitación nerviosa" (Miramont, 18 ago. 1876). La descripción que hizo del éxtasis de Bergadieu recuerda claramente a las imágenes de mujeres histéricas en las llamadas "actitudes pasionales" de éxtasis, crucifixión y oración durante la tercera fase del ataque histérico, representada en la Iconographie photographique de la Salpêtrière de Désiré-Magloire Bourneville y Paul Regnard (1876-1880). Como Georges Didi-Huberman (2003, p.246) ha señalado, muchas de las imágenes de la Iconographie eran "imágenes de pecado" saturadas de sexualidad. En ellas, Bourneville describió frecuentemente la actitud de la histérica con el verbo jouir, que en francés significa tanto disfrutar como tener un orgasmo.

Las imágenes de la Iconographie, así como la estrecha relación entre la histérica y la prostituta, eran cuestiones conocidas que seguramente no escaparon al padre Miramont. Así, no parece inapropiado afirmar que el párroco exageró el erotismo del éxtasis de Bergadieu en sus informes para hacer más evidente el vínculo entre su pretendido misticismo y el ataque histérico. De hecho, si nos fijamos en otras descripciones del éxtasis de Bergadieu, llevadas a cabo por algunos de sus visitantes, entre ellos médicos, el componente erótico queda matizado o no aparece por ningún lado. Por ejemplo, el informe de los doctores Émile Mauriac y Henri Verdalle (1875, p.356) contradice el testimonio del padre Miramont. Allí, los médicos mencionan que, durante el éxtasis, Bergadieu parecía especialmente preocupada por mantener las sábanas y la enagua en su lugar para evitar revelar su cuerpo.

Como era de esperar, ninguno de estos tres casos de presunto misticismo fue reconocido por los obispos. Estos emprendieron varias medidas de aislamiento contra las "santas", como el hecho de no permitirles recibir visitas o sustituir a los confesores que les eran favorables. Además, los párrocos fueron instruidos de llevar a cabo acciones para volver a las mujeres a la "normalidad", como por ejemplo negarles la comunión diaria o incluso la confesión (Hermier, 31 ago. 1886; Roberdel, 1987). En consecuencia, las supuestas místicas dijeron sentirse abandonadas en su propia diócesis (Fillastre, 9 abr. 1875). Laurentine Billoquet, por ejemplo, terminó por mudarse a Dijon, donde vivió bajo una nueva identidad y obtuvo fama de vidente (Maître, 1993b).

Los informes de los párrocos influyeron sin duda en su descrédito, tanto eclesiástico como popular. A nivel eclesiástico, las medidas disuasorias emprendidas por los obispos prueban que los párrocos les convencieron de que se trataban de casos de misticismo simulado. Como hemos visto, el discurso médico sirvió de apoyo a este argumento. A nivel popular, la falta de apoyo del obispado impidió que los cultos no oficiales proliferaran. Con la excepción del 
culto a Jahenny, del cual todavía encontramos rastros de una débil "devoción desviada" a ojos de la diócesis de Nantes, los cultos de Billoquet y Bergadieu no sobrevivieron e incluso desaparecieron antes de la muerte de la mística (Lachapelle, 2017; Roberdel, 1987). En este sentido, la unión de la religión y la ciencia permitió, en ocasiones, combatir supuestos fanatismos al relegar casos de pretendida santidad al dominio psicopatológico.

\section{Consideraciones finales}

Mucho se ha escrito sobre la patologización de la religión en Francia durante el siglo XIX, así como sobre la forma en que los católicos se enfrentaron a ella. Como hemos tratado de mostrar en este artículo, la Iglesia católica no solo sufrió, sino que también se benefició de este proceso de patologización cuando apuntaba a casos problemáticos de místicas o "santas vivientes". El contexto médico y psiquiátrico fue una fuente de inspiración para los sacerdotes. Como ha apuntado Tiago Pires Marques $(2016,2017)$ en los casos de visionarias y estigmatizadas portuguesas de principios del siglo XX, conceptos psiquiátricos utilizados para atacar la autenticidad de la experiencia religiosa podían ser reformulados dentro de la religión para denunciar presuntos fraudes, sin por ello negar la existencia de la experiencia mística verdadera.

En Francia, teólogos como Jean-Corneille Debreyne y Joseph de Bonniot redactaron conocidos ensayos donde se oponía la histeria y la santidad, y donde se enseñaba a los sacerdotes a diferenciar entre ambas cuando se enfrentaban a supuestos casos de misticismo en sus parroquias. Con frecuencia, las autoridades eclesiásticas vieron el entusiasmo religioso que rodeaba las santas vivientes como una señal de fanatismo que debía reprimirse. Bajo tales circunstancias, y auspiciados por discursos como los de Bonniot y Debreyne, los sacerdotes usaron estrategias retóricas para presentar estos casos como ejemplos de desviación religiosa con carácter patológico, en consonancia con los discursos psiquiátricos de la época.

Los informes privados de varios párrocos sobre las místicas extáticas y estigmatizadas Laurentine Billoquet, Marie-Julie Jahenny y Berguille Bergadieu demuestran que el clero utilizó la medicalización de la religión en su día a día. Mediante los paralelismos entre la actitud y las experiencias de los santos y místicos reconocidos por la Iglesia, y el comportamiento y las características atribuidas a las histéricas en la literatura médica, los párrocos argumentaron que Billoquet, Jahenny y Bergadieu simularon sus fenómenos místicos, en su mayoría éxtasis, estigmas y visiones. Como en los manuales médicoteológicos, su estrategia retórica se basó en el uso de la terminología psiquiátrica para descalificar a las supuestas místicas y presentar su comportamiento como desviado o patológico ante la Iglesia.

El uso de la terminología médica no comportó necesariamente la refutación científica de los fenómenos. De hecho, esta apropiación discursiva se dio de forma cotidiana, con o sin hacer referencia a los exámenes médicos de las místicas, practicados ya fuese mediante el requerimiento del obispo o de forma independiente. En este sentido, el uso de términos psiquiátricos por parte de los párrocos sirvió ante todo como estrategia retórica de demarcación. Esta clase de estrategias, mencionadas dentro del boundary-work o el estudio de la formación de límites epistemológicos, sirvieron al clero para demarcar la "auténtica" 
experiencia mística de la simulada o "desviada". Así, en manos del clero, la patologización de la experiencia religiosa no era necesariamente una amenaza; al contrario, podía servir para proteger el misticismo y la santidad aprobados por la Iglesia, excluyendo, mediante el uso de la retórica psiquiátrica, los casos no reconocidos por las autoridades eclesiásticas.

\section{AGRADECIMIENTOS}

Esta investigación ha recibido financiamiento del European Research Council (ERC) bajo el programa de investigación e innovación de la Unión Europea H2020, mediante la beca de investigación n.637908. La autora quisiera agradecer a los dos revisores anónimos cuyos comentarios contribuyeron a mejorar este artículo.

\section{REFERENCIAS}

ARNAUD, Sabine. On hysteria: the invention of a medical category between 1670 and 1820. Chicago: The University of Chicago Press, 2015.

AUDRIAN, A. Informe sur Marie-Julie Jahenny, 18 oct. 1873. Fonds Marie-Julie Jahenny, 5F2/25 (Archives Historiques du Diocèse de Nantes, Nantes), 15 oct. 1877.

BACARLETT PÉREZ, María Luisa; LECHUGA DE LA CRUZ, Amalia María. Canguilhem y Foucault: de la normatividad a la normalización. Ludus Vitalis, v.17, n.31, p.65-85, 2009.

BALL, Benjamin. La stigmatisée de S. L'Encéphale, v.1, p.361-368, 1881.

BLACKBOURN, David. Marpingen: apparitions of the Virgin Mary in Bismarckian Germany. Oxford: Clarendon, 1993.

BONNIOT, Joseph de. Opposition entre l'hystérie et la sainteté. Paris: Letouzey et Ané, 1886.

BONNIOT, Joseph de. Le miracle et les sciences médicales: hallucination, apparitions, extase, fausse extase. Paris: Didier, 1879.

BOUFLET, Joachim. Les stigmatisés. Paris: Cerf, 1996.

BOURNEVILLE, Désiré-Magloire; REGNARD, Paul. Iconographie photographique de la Salpêtrière. 3 v. Paris: Progrès Médical, 1876-1880.

BOURRU, Henri; BUROT, Prosper F. Variations de la personnalité. Paris: Baillière, 1888.

BRIERRE DE BOISMONT, Alexandre. Des hallucinations ou histoire raisonnée des apparitions, des visions, des songes, de l'extase, du magnétisme et du somnambulisme. Paris: Baillière, 1845.

BURTON, Richard. Holy tears, holy blood: women, catholicism, and the culture of suffering in France, 1840-1970. Ithaca: Cornell University Press, 2005.

BUSTOS-CARDONA, Tatiana et al. Ayunadoras (inedias) y cuerpos incorruptos: fronteras entre medicina y religión en Galicia (España) y norte de Portugal en los siglos XIX y XX. Siso Saúde, invierno, n.56-57, p.227-239, 2015.

CANGUILHEM, Georges. Le normal et le pathologique. Paris: PUF, 2003.

CARROY, Jacqueline. Le mal de Morzine: de la possession à l'hystérie, 1857-1877. Paris: Solin, 1981.

CERTEAU, Michel de. Mystic historicities. In: Girard, Luce (org.). The mystic fable, v.2: sixteenth and seventeenth centuries. Chicago: Chicago University Press, 2015. p.1-22.

CHANTIN, Jean-Pierre. Des "sectes" dans la France contemporaine, 1905-2000: contestations ou innovations religieuses? Paris: Privat, 2004.

CHARCOT, Jean-Martin; RICHER, Paul. Les démoniaques dans l'art. Paris: Delahaye et Lecrosnier, 1887.

COFFIN, Jean-Christophe. Alfred Maury ou l'analyse profane de la médecine mentale. In: Carroy, Jacqueline; Richard, Nathalie (org.). Alfred Maury, érudit et rêveur: les sciences de l'homme au milieu du XIXe siècle. Rennes: Presses Universitaires de Rennes, 2007. p.89-103.

CRAIG, William Lane. The problem of miracles: a historical and philosophical perspective. In: Wenham, David; Blomberg, Craig (org.). Gospel perspectives VI. Sheffield: JSOT Press, 1986. p.940.

CURICQUE, Jean-Marie. Voix prophétiques ou signes, apparitions et prédictions modernes. Paris: Victor Palmé, 1872.

DAURELLE, Abbé. Les événements de Fontet d'après les principes de Saint Thomas. Rome: Imprimerie de Rome, 1878.

DEBREYNE, Jean-Corneille. La théologie morale et les sciences médicales. Paris: Librairie Poussielgue, 1884. 
DEBREYNE, Jean-Corneille. Essai sur la théologie morale considérée dans ses rapports avec la physiologie et la médecine. Paris: Librairie Poussielgue, 1868.

DESMAISONS. Observations lues à la société de médecine et de chirurgie de Bordeaux. Gazette Médicale de Bordeaux, v.5, n.4, p.61-71, 1876.

DIDI-HUBERMAN, Georges. The invention of hysteria. Charcot and the photographiciconography of the Salpetrière. Cambridge: The MIT Press, 2003.

DIÉGUEZ-GÓMEZ, Antonio. Hipnotismo y medicina mental en la España del siglo XIX. In: Montiel, Luis; González de Pablo, Ángel (org.). En ningún lugar en parte alguna: estudios sobre la historia del magnetismo animal y del hipnotismo. Madrid: Frenia, 2003. p.197-228.

DIOCÈSE DE ROUEN. La Semaine Religieuse du Diocèse de Rouen, p.1007, 15 oct. 1881.

DUFFIN, Jacalyn. Medical miracles: doctors, saints, and healing in the Modern World. Oxford: Oxford University Press, 2009.

EDELMAN, Nicole. Lo oculto y las terapéuticas espiritistas del espíritu y del cuerpo en Francia (1850-1914): de la creencia al saber y vuelta. Asclepio, v.58, n.2, p.39-62, 2006.

EDELMAN, Nicole. Les métamorphoses de l'hystérique: du début du XIXe siècle à la Grande Guerre. Paris: La Découverte, 2003.

EROS, John. The positivist generation of French republicanism. Sociological Review, v.3, n.2, p.255-277, 1955.

FILLASTRE, E. Visite faite à Berguille le 9 avril 1875. Dossier Marie (Berguille) Bergadieu (Archives Diocésaines de Bordeaux, Burdeos). 9 abr. 1875 .

FRANCO, Juan-José. El hipnotismo puesto en moda: historia y disquisición científica. Barcelona: La Hormiga de Oro, 1888.

GIERYN, Thomas F. John Tyndall's Double boundary-work: science, religion, and mechanics in Victorian England. In: Gieryn, Thomas F. Cultural boundaries of science: credibility on the line. Chicago: The University of Chicago Press, 1999. p.37-64.

GIERYN, Thomas F. Boundary-work and the demarcation of science and non-science: strains and interests in professional ideologies of scientists. American Sociological Review, v.48, n.6, p.781-795, 1983.

GIRARD, A. Rapport sur l'extatique de Fontet. Union Médicale de la Seine-Inférieure, v.15, p.84-87, 1876.
GOLDSTEIN, Jan. Hysteria complicated by ecstasy: the case of Nanette Leroux. Princeton: Princeton University Press, 2011.

GOLDSTEIN, Jan. The hysteria diagnosis and the politics of anticlericalism in late nineteenthcentury France. The Journal of Modern History, v.54, n.2, p.209-239, 1982.

GRAUS, Andrea. Ciencia y espiritismo en España, 1880-1930. Granada: Comares, 2019.

GRAUS, Andrea. Ciencia y pseudociencia: el boundary-work como herramienta historiográfica. In: Bellver Loizaga, Vicente et al. (org.). "Otras voces, otros ámbitos": los sujetos y su entorno. Nuevas perspectivas de la historia sociocultural. Valencia: Asociación de Historia Contemporánea; Universitat de València, 2015. p.200-202.

GUILLEMAIN, Hervé. Diriger les consciences, guérir les âmes: une histoire comparée des pratiques thérapeutiques et religieuses (1830-1939). Paris: La Découverte, 2006.

HACKING, Ian. The normal state. In: Hacking, Ian. The taming of chance. Cambridge:

Cambridge University Press, p.160-169, 1990.

HARRIS, Ruth. Lourdes: body and spirit in the secular age. New York: Penguin, 2008.

HERMIER, Ferdinand. Carta al vicario general de Rouen. Affaire Laurentine Billoquet, 791 (Archives Diocésaines de Rouen, Rouen). 31 ago. 1886.

HERMIER, Ferdinand. Carta al vicario general de Rouen. Affaire Laurentine Billoquet, 791 (Archives Diocésaines de Rouen, Rouen). 17 feb. 1886.

HERMIER, Ferdinand. Carta al vicario general de Rouen. Affaire Laurentine Billoquet, 791 (Archives Diocésaines de Rouen, Rouen). 22 dic. 1885.

HERMIER, Ferdinand. Diario de Ferdinand Hermier. Affaire Laurentine Billoquet, 791 (Archives Diocésaines de Rouen, Rouen), 18831886.

IMBERT-GOURBEYRE, Antoine. L'hypnotisme et la stigmatisation. Paris: Bloud, 1899.

IMBERT-GOURBEYRE, Antoine. La stigmatisation: l'extase divine et les miracles de Lourdes: réponse aux libres-penseurs. ClermontFerrand: Libraire Catholique, 1894.

IMBERT-GOURBEYRE, Antoine. Informes sobre Marie-Julie Jahenny para monseñor Lecoq. Fonds Marie-Julie Jahenny, 5F2/37 (Archives Historiques du Diocèse de Nantes, Nantes), 1878-1892. 
IMBERT-GOURBEYRE, Antoine. Les stigmatisées, v.1-2. Paris: Victor Palmé. 1873.

JANET, Pierre. De l'angoisse à l'extase, v.1. Paris: Société Pierre Janet, 1975.

JANET, Pierre. L'Automatisme psychologique: essai de psychologie expérimentale sur les formes inférieures de l'activité humaine. Paris: Félix Alcan, 1898.

JOUON; VIGNAUX. Informe médico de la investigación diocesana de Marie-Julie Jahenny (1873). Fonds Marie-Julie Jahenny, 5F2/26 (Archives Historiques du Diocèse de Nantes, Nantes). 29 mar. 1873.

KLANICZAY, Gábor. The stigmatized Italian visionary and the devout French physician: Palma Matarrelli d'Oria and docteur Imbert Gourbeyre. Women's History Review, v.29, n.1, p.109-124, 2020.

KSELMAN, Thomas. Miracles and prophecies in nineteenth-century France. New Brunswick: Rutgers University Press, 1983.

LACHAPELLE, Sofie. Prophecies of pilgrimage: the rise and fall of Marie Bergadieu, the ecstatic of Fontet. In: Van Osselaer, Tine; De Smaele, Henk; Wils, Kaat (org.). Sign or symptom? Exceptional corporeal phenomena in religion and medicine in the 19th and 20th centuries. Leuven: Leuven University Press, 2017. p.57-67.

LAKHDARI, Sadi. Hypnose, hystérie, extase: de Charcot à Freud. Savoirs et cliniques, v.1, n.8, p.201-209, 2007.

LE MALÉFAN, Pascal, EVRARD, Renaud, ALVARADO, Carlos S. Spiritist delusions and spiritism in the nosography of French psychiatry (1850-1950). History of Psychiatry, v.24, n.4, p.477-491, 2013.

MAÎTRE, Jacques. De Bourneville à nos jours: interprétations psychiatriques de la mystique. Évolution Psychiatrique, v.64, p.765-778, 1999.

MAÎTRE, Jacques. Mystique et féminité: essai de psychanalyse sociohistorique. Paris: Cerf, 1997.

MAÎTRE, Jacques. Une inconnue célèbre: la Madeleine Lebouc de Janet. Paris: Anthropos, 1993a.

MAÎTRE, Jacques. Les stigmates de l'hystérique et la peau de son évêque: Laurentine Billoquet (18621936). Paris: Anthropos, 1993b.

MARGRY, Peter Jan. New transnational religious cultures: the networks and strategies of deviant devotions in contemporary Europe. In: PaládiKovács, Attila (org.). Times, places, passages: ethnological approaches in the new millennium. Budapest: Akademia Kiado, 2004. p.205-213.
MARQUES, Tiago Pires. Experiencing religion and medicine: Marian apparitions and victim souls in Portugal, 1920-1950. In: Van Osselaer, Tine; De Smaele, Henk; Wils, Kaat (org.). Sign or symptom? Exceptional corporeal phenomena in religion and medicine in the 19th and 20th centuries. Leuven: Leuven University Press, 2017. p.141-162.

MARQUES, Tiago Pires. Intimações do êxtase feminino: dois momentos da cultura da histeria em Portugal. In: Wadi, Yonissa Marmitt (org.). Narrativas sobre loucuras, sofrimentos e traumas. Curitiba: Máquina de Escrever, 2016. p.93-117.

MARQUES, Tiago Pires. Mystique, politique et maladie mentale: historitcités croisées (France, c.1830-c.1900). Revue d'Histoire des Sciences Humaines, v.2, n.23, p.37-74, 2010.

MAURIAC, Émile; VERDALLE, Henri. Seánce du 10 décembre 1875. Mémoires et bulletins de la Société de Médecine et de Chirurgie de Bordeaux, p.342-469. Fonds Jacques Maître, EHESS/PR/750 (Archives Nationales, Pierrefittesur-Seine), 1875.

MAURY, Serge. Une secte janséniste convulsionnaire sous la Révolution Française: les Fareinistes (17831905). Paris: L'Harmattan, 2019.

MAURY, Alfred. La magie et l'astrologie dans L'antiquité et au Moyen Âge. Paris: Didier, 1860.

MAURY, Alfred. Les mystiques extatiques et les stigmatisés. Annales Médico-psychologiques, v.1, n.2, p.181-232, 1855.

MAURY, Alfred. De l'hallucination envisagée au point de vue philosophique et historique ou examen critique de l'opinion émise par M. Brierre de Boismont. Annales Médicopsychologiques, v.5, p.317-338, 1845.

MAZZONI, Cristina. Saint hysteria: neurosis, mysticism and gender in European culture. Ithaca: Cornell University Press, 1996.

MICALE, Mark S. Approaching hysteria: disease and its interpretations. Princeton: Princeton University Press, 1995.

MIRAMONT, J.B. Carta al Vicario de Burdeos. Dossier Marie (Berguille) Bergadieu (Archives Diocésaines de Bordeaux, Burdeos). 18 ago. 1876.

MONTIEL, Luis. Daemoniaca: curación mágica, posesión y profecía en el marco del magnetismo animal romántico. Barcelona: MRA, 2006.

MÜLBERGER, Annette (org.). Los límites de la ciencia: espiritismo, hipnotismo y el estudio de los fenómenos paranormales. Madrid: CSIC, 2016. 
MULTON, Hilaire. Prophétesses et prophéties dans la seconde moitié du pontificat de Pie IX (1859-78): entre défense du pouvoir temporel et apocalypse hétérodoxe. Dimensioni e Problema della Ricerca Storica, v.1, p.131-159, 2003.

OGORZELEC, Laetitia. L'évolution de l'expertise médicale des guérisons de Lourdes au regard de la 'conversation de gestes'. Archives de Sciences Sociales des Religions, v.166, p.221-241, avril-juin 2014.

PORTER, Roy. Quacks: fakers and charlatans in medicine. Stroud: Tempus, 2003.

RENAN, Ernest. La vie de Jésus. Paris: Michel Lévy, 1863.

RICHARD, Nathalie. Le "merveilleux réel": Maury et l'histoire des aberrations de l'esprit humain. In: Carroy, Jacqueline, Richard, Nathalie (org.). Alfred Maury, érudit et rêveur: les sciences de l'homme au milieu du XIXe siècle. Rennes: Presses Universitaires de Rennes, 2007. p.73-88.

RICHER, Paul. Études cliniques sur la grande hystérie ou hystéro-épilepsie. Paris: Delahaye et Lecrosnier, 1881.

RICHET, Charles. Les démoniaques d'aujourd'hui. Revue des Deux Mondes, v.3, n.37, p.340-372, 1880.

ROBERDEL, Pierre. Marie-Julie Jahenny: la stigmatisée de Blain. Montsûrs: Résiac, 1987.

SANDONI, Luca. Political mobilizations of ecstatic experiences in late nineteenth-century catholic France: the case of doctor Antoine Imbert-Gourbeyre and his 'stigmatisées' (18681873). Disputatio Philosophica: International Journal of Philosophy and Religion, v.16, p.18-41, 2015.

SIMON-NAHUM, Perrine. Le scandale de la Vie de Jésus de Renan: du succès littéraire comme mode d'échec de la science. Mil Neuf Cent: Revue d'Histoire Intellectuelle, v.1, n.25, p.61-74, 2007.

STRAUSS, David. Vie de Jésus ou examen critique de son histoire, v.1-2. Trad. Émile Littré. Paris: Librarie Philosophique de Ladrange, 1856.

SZABO, Jason. Seeing is believing? The form and substance of French medical debates over Lourdes. Bulletin of the History of Medicine, v.76, n.2, p.199-230, 2002.

VAN OSSELAER, Tine; DE SMAELE, Henk; WILS, Kaat (org.). Sign or symptom? Exceptional corporeal phenomena in religion and medicine in the 19th and 20th centuries. Leuven: Leuven University Press, 2017.

VAN OSSELAER, Tine et al. The devotion and promotion of stigmatics in Europe, c. 1800-1950. Between saints and celebrities. Leiden: Brill, 2020.

VIDAL, Fernando. Miracles, science and testimony in post-tridentine saint-making. Science in Context, v.20, n.3, p.481-508, 2007.

WINTER, Alison. Mesmerized: powers of mind in victorian Britain. Chicago: University of Chicago Press, 1998. 